\title{
Ocular neuromyotonia
}

\author{
Ricardo Soares-dos-Reis, ${ }^{1,2}$ Ana Inês Martins, ${ }^{3}$ Ana Brás, ${ }^{3}$ \\ Anabela Matos, ${ }^{3}$ Conceição Bento, ${ }^{3}$ João Lemos ${ }^{3,4}$
}

- Additional material is published online only. To view please visit the journal online (http://dx.doi.org/10.1136/ practneurol-2017-001866).

${ }^{1}$ Neurology Department, São João Hospital Centre, Porto, Portugal

${ }^{2}$ Faculty of Medicine, Porto University, Porto, Portugal ${ }^{3}$ Neurology Department, Coimbra University Hospital Centre, Coimbra, Portugal

${ }^{4}$ Faculty of Medicine, Coimbra University, Coimbra, Portugal

\section{Correspondence to}

Dr João Lemos, Department of Neurology, Coimbra University Hospital Centre, Coimbra 3000075, Portugal; merrin72@ hotmail.com

RS--R and AIM contributed equally.

Accepted 31 January 2018
To cite: Soares-dos-Reis $R$ Martins Al, Brás A, et al. Pract Neurol Epub ahead of print: [please include Day Month Year]. doi:10.1136/ practneurol-2017-001866

\section{ABSTRACT}

Ocular neuromyotonia is a rare, albeit treatable, ocular motor disorder, characterised by recurrent brief episodes of diplopia due to tonic extraocular muscle contraction. Ephaptic transmission in a chronically damaged ocular motor nerve is the possible underlying mechanism. It usually improves with carbamazepine. A 53-year-old woman presented with a 4-month history of recurrent episodes of binocular vertical diplopia (up to 40/day), either spontaneously or after sustained downward gaze. Between episodes she had a mild left fourth nerve palsy. Sustained downward gaze consistently triggered downward left eye tonic deviation, lasting around $1 \mathrm{~min}$. MR scan of the brain was normal. She improved on starting carbamazepine but developed a rash that necessitated stopping the drug. Switching to lacosamide controlled her symptoms.

\section{CASE REPORT}

A previously healthy 53-year-old woman presented with a 4-month history of recurrent short episodes of binocular vertical diplopia lasting around $1 \mathrm{~min}$, occurring up to 40 times per day. On

FIELD OF LEFT EYE (fixing with right eye)

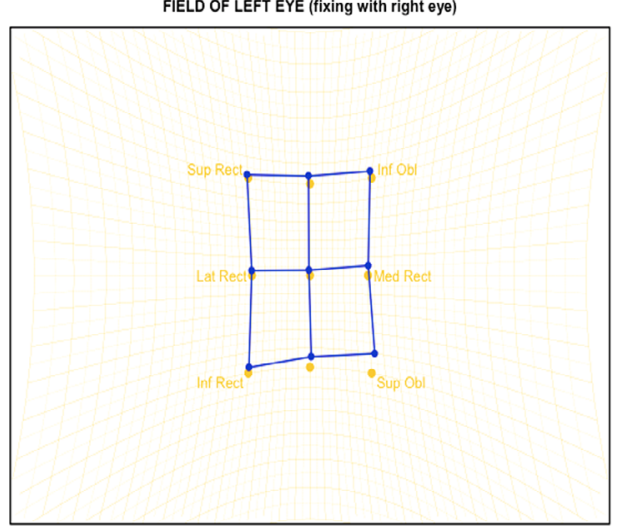

examination between episodes, her ocular ductions were full and there was no ocular misalignment on alternate cover testing. However, on Hess test there was mild vertical strabismus, that is, hyperdeviation of the left eye, increasing in right and downward gaze (figure 1), consistent with a left fourth nerve palsy. Sustained downward gaze consistently triggered marked left eye hypodeviation lasting around $1 \mathrm{~min}$ and associated with vertical diplopia (online supplementary video 1 ). The remainder of the exam was unremarkable. MR scan of the brain, serum thyroid hormone panel, serum antiacetylcholine receptor and antimuscle-specific kinase antibody panel, and repetitive nerve stimulation were normal. We diagnosed left fourth nerve ocular neuromyotonia, and started carbamazepine $200 \mathrm{mg}$ twice a day, with complete resolution of her symptoms. However, 1 week later, she developed an adverse cutaneous drug reaction, and so we stopped the carbamazepine. Subsequent dermatological testing recommended against her using oxcarbazepine, eslicarbazepine acetate, phenobarbital or phenytoin. As her diplopia recurred, she

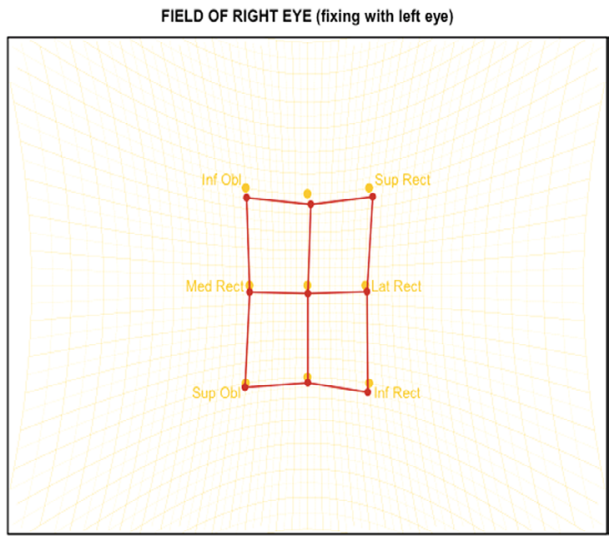

Figure 1 Hess test. There is a limitation of infraduction of the left eye, which worsens in right and downgaze (best seen in the left segment) (the nine cardinal positions of gaze in the left segment are represented by blue dots (left eye) and yellow dots (right eye), and in the right segment by yellow dots (left eye) and red dots (right eye). Note that the left eye field is slightly above the right eye field, particularly in right and downgaze, reflecting the presence of vertical strabismus due to an underaction of the left superior oblique muscle (ie, left fourth nerve palsy). (In the Hess test, the patient moves a spot seen only by one eye in a screen until it appears superimposed on a second spot seen by the other eye, in order to measure ocular alignment.) 


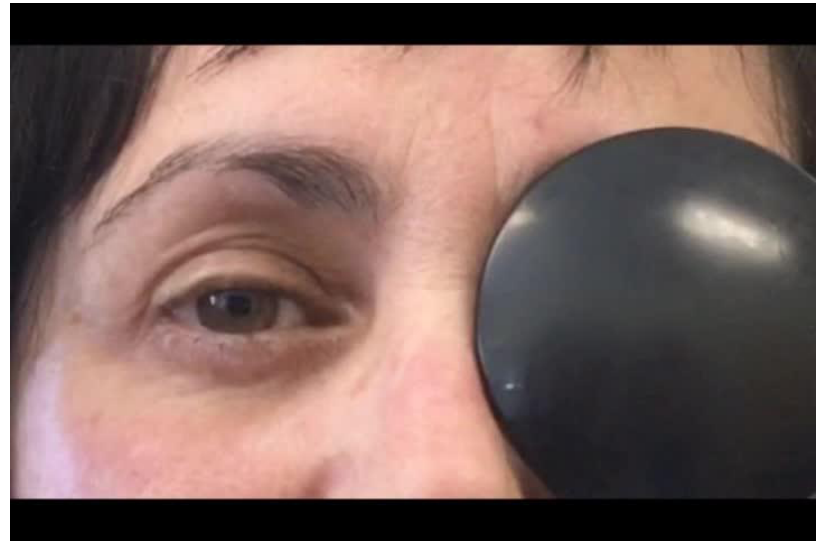

Video 1 See online for the full video.

\section{Key Points}

- Ocular neuromyotonia is characterised by tonic spasms involving one or more extraocular muscles.

- Ocular neuromyotonia should be considered in the differential diagnosis of recurrent diplopia, particularly when following previous nerve injury.

- Patients with suspected ocular neuromyotonia should undergo MR scan of the brain to exclude secondary causes of ocular neuromyotonia.

- Ocular neuromyotonia responds to carbamazepine, although other sodium channel blockers, including lacosamide, may be effective.

\section{Referee's comment}

We asked Dr Mark Lawden, who refereed this paper, to help readers to distinguish between ocular neuromyotonia and superior oblique myokymia. Here is his reply

In ocular neuromyotonia the eye gets temporarily stuck after looking in the direction of the affected muscle causing sustained diplopia on looking back the primary position. This gradually goes off after a minute or two as in the video in this paper. The cause may be compression, prior irradiation or idiopathic.

https://www.youtube.com/watch?v=0NAb70xWZjQ (accessed 15/02/2018)

In superior oblique myokymia there are repetitive very brief torsional movements of the eye causing brief vertical diplopia. The cause is probably microvascular compression as with trigeminal neuralgia and hemifacial spasm.

https://www.youtube.com/watch?v=HwsJvCOC6_Q (accessed 15/02/2018)

You can just about see it in the above video clip (it's very subtle).

was started on lacosamide $100 \mathrm{mg}$ twice a day with a prompt and sustained clinical response (online supplementary video 1 ).

\section{DISCUSSION}

Ocular neuromyotonia is a rare yet treatable cause of transient diplopia. It is due to a spasm of one or more extraocular muscles that may occur spontaneously and after holding eccentric gaze. ${ }^{1}$ It can involve any extraocular muscle, including the levator palpebrae superioris, and lasts between seconds and 3-4 min. ${ }^{2}$ It most commonly occurs in the setting of cranial irradiation, nerve compression of vascular or meningeal origin, and autoimmune disorders (eg, myasthenia gravis and thyroid eye disease). ${ }^{1}$ Many cases are idiopathic and are frequently accompanied by mild paresis of the affected muscle in between episodes, ${ }^{2}$ as in this case. The pathophysiology probably relates to nerve demyelination and ephaptic transmission, although repatterning of central circuits and a mechanism similar to that of systemic neuromyotonia (ie, calcium channel dysfunction) are alternative causes. ${ }^{2}$ As in other ephaptic transmission conditions, voltage-gated sodium channel (VGSC) blockers (ie, carbamazepine, oxcarbazepine, phenytoin, lamotrigine) are recommended, although a few reported refractory cases undergo surgical microvascular decompression. ${ }^{3}$ In this case, given the occurrence of a carbamazepine-induced cutaneous adverse reaction, we considered lacosamide, given the risk of adverse drug reaction with other VGSC blockers, its low risk of cross-reactivity, side-effect profile and action mechanism. Specifically, both carbamazepine and lacosamide act on the VGSC. However, carbamazepine stabilises the channel in the fast-inactivating phase in a use-dependent fashion, while lacosamide stabilises it in the slow-inactivating phase, with weak use dependence, thus decreasing VGSC availability. ${ }^{4}$ Furthermore, carbamazepine may also act on calcium channels, while lacosamide appears to have no effect on those channels. ${ }^{4}$ Although the clinical correlate of these physiological differences is elusive, efficacy in this patient was not hampered by the differences in mechanism of action.

In conclusion, this case illustrates ocular neuromyotonia as a rare cause of transient diplopia, which fully responded to lacosamide. Our observation expands the therapeutic armamentarium for ocular neuromyotonia.

Contributors All authors were responsible for the clinical care of the patient. The initial draft was written by RSR and AIM. AIM and JL recorded the patient video. All authors reviewed and contributed to the final manuscript.

Competing interests None declared.

Patient consent Obtained.

Provenance and peer review Not commissioned; externally peer reviewed. This paper was reviewed by Mark Lawden, Leicester, UK.

(c) Article author(s) (or their employer(s) unless otherwise stated in the text of the article) 2018. All rights reserved. No commercial use is permitted unless otherwise expressly granted. 


\section{REFERENCES}

1 Lueck CJ. Infranuclear ocular motor disorders. Handb Clin Neurol 2011;102:281-318.

2 Roper-Hall G, Chung SM, Cruz OA. Ocular neuromyotonia: differential diagnosis and treatment. Strabismus 2013;21:131-6.
3 Strupp M, Dieterich M, Brandt T, et al. Therapy of Vestibular Paroxysmia, Superior Oblique Myokymia, and Ocular Neuromyotonia. Curr Treat Options Neurol 2016;18:34.

4 Rogawski MA, Tofighy A, White HS, et al. Current understanding of the mechanism of action of the antiepileptic drug lacosamide. Epilepsy Res 2015;110:189-205. 


\section{DN Ocular neuromyotonia}

Ricardo Soares-dos-Reis, Ana Inês Martins, Ana Brás, Anabela Matos, Conceição Bento and João Lemos

Pract Neurol published online February 21, 2018

Updated information and services can be found at:

http://pn.bmj.com/content/early/2018/02/21/practneurol-2017-001866

\section{These include:}

References This article cites 4 articles, 0 of which you can access for free at: http://pn.bmj.com/content/early/2018/02/21/practneurol-2017-001866 \#ref-list-1

Email alerting

Receive free email alerts when new articles cite this article. Sign up in the service box at the top right corner of the online article.

\section{Notes}

To request permissions go to:

http://group.bmj.com/group/rights-licensing/permissions

To order reprints go to:

http://journals.bmj.com/cgi/reprintform

To subscribe to BMJ go to:

http://group.bmj.com/subscribe/ 